\title{
Network Criticality and the Node-Place-Design Model: Classifying metro station areas in Greater London
}

\author{
Yuerong Zhang $^{\mathrm{a}, \mathrm{b}}$ * Stephen Marshall $^{\mathrm{a}} \&$ Ed Manley $^{\mathrm{b}}$ \\ ${ }^{a}$ Bartlett School of Planning, University College London, Gower St, London WC1H 0NN, UK \\ ${ }^{\mathrm{b}}$ Centre for Advanced Spatial Analysis, University College London, Gower St, London WC1E 6BT, UK \\ * Corresponding author: yuerong.zhang.14@ucl.ac.uk
}

\begin{abstract}
Centralisation of activities and developments around metro station areas is a key transit-oriented development (TOD) policy to encourage more public transport travel through providing maximum access to passengers, thereby enhancing economic efficiency, health, well-being and social inclusion. The node-place-design model is an analytical approach, which investigates the interaction between land use, transportation and the walking friendliness around station areas. Nevertheless, current research focuses on the role station areas plays at the local scale, and little consideration is given to the strategic network (system) level. In this research, we combine a strategic network indicator (criticality) with the node-place-design model to gain deeper insights into London metro station areas in terms of their transit-oriented-development at both local and system levels. Our research has three principal findings: first, most of station areas in Greater London show balanced situations between transport and land use development, except for some stations with a non-walking friendly environment such as Victoria station. Second, the two-tier approach finds that the system criticality of each station area can vary substantially even within the same cluster grouped by the original nodeplace-design model. Therefore, identifying station groups with relatively high network criticality and relatively low node-place-design score is of potential value. The promising transport connection and less-developed conditions of those station areas could help policymakers locate an intensificationdiversification TOD group. Conversely, locations with high node-place-design values but low criticality could point to stations suitable for network expansion (new lines or interchanges). Third, the result reconfirms the value of introducing the third dimension - design - into the TOD evaluation of stations at the local scale. The relatively low correlation between node and design value is consistent with previous findings that a transport service-intensive and functionally diverse metro station area does not necessarily produce an accessible friendly walking environment. Overall, the paper provides a platform for further studies integrating strategic network and node-place-design attributes.
\end{abstract}

\section{Keywords:}

Metro station; Transit-oriented development; Node-place-design model; Network analysis; Criticality; Greater London 


\section{Introduction}

Metro systems play an increasingly important role in assuring public transport accessibility and reduction of traffic pollution and congestion, as well as providing opportunities for urban regeneration and revitalization (Conticelli, 2011). Furthermore, as metro systems serve a decisive role in urban development (Chorus and Bertolini, 2011), metro stations are no longer just transport infrastructure for movement, but 'activity engines' for shaping urban developments in their surrounding areas. This dual role of a metro station fits with the concept of transit-oriented development (TOD), which is generally defined as "a mixed-use community that encourages people to live near transit services and to decrease their dependence on driving" (Calthorpe, 1993). As a widely encouraged and adopted urban strategy, policy and planning approach, TOD aims at encouraging a better integration of transportation-driven supply and land-use driven demand while improving pedestrian friendliness (Dittmar and Ohland, 2012, Cervero and Kockelman, 1997, Sung and Oh, 2011, Higgins and Kanaroglou, 2016). The London Underground - henceforth referred to as the London metro system handles up to 5 million passengers' journeys per day, which take up roughly around $12 \%$ of total Greater London daily journeys (TfL, 2017; TfL, 2018). The metro usage will upsurge because London now is facing another wave of population growth, reaching 10.8 million in 2041 (GLA, 2018). To accommodate growth while protecting the Green Belt, the implementation of TOD has been considered as a promising solution. Nevertheless, there is a lack of knowledge concerning TOD of metro station areas in Greater London.

The major debate concerning TOD is interpreting the common characteristics of its built environment, such as mixed use, density, design, collaboration between land and transport, and proximity (Ewing and Cervero, 2001, Cervero and Kockelman, 1997, Sung and Oh, 2011, Nasri and Zhang, 2014, Nasri and Zhang, 2012). Gradually different metrics like socio-economic and transit services (Lund et al., 2004) have been built into the understanding of the relations between TOD common elements and vehicle miles travelled (VMT) (Naris and Zhang, 2014) or transit ridership (Cervero, 2007; Cervero and Dai, 2014). Recent research illustrates emerging interests in developing typologies of transit areas (Higgins and Kanaroglou, 2016) because the classification can provide planners and policymakers with an evidence-based reference to identify comparable stations. The other benefit is to reduce the complexity of management and ensure consistency of actions across large geographic regions (Zemp et al., 2011). The earliest evaluation of station area TOD can be traced back to the node-place model introduced by Bertolini (1996), which is essentially an analytical framework for assessing station areas in both transport and land use aspects. A proliferation of studies follows to develop and extend 'the node-place model', among which the most notable is that by Vale (2015), who suggested adding the third dimension 'design' to assess pedestrian accessibility around stations. That is to say, to examine if station areas achieve an effective integration of transport and land use, current studies mainly focus on three dimensions: 1) multimodal accessibility of the station; 2) land use diversity and intensity, and 3) pedestrian-oriented design (Vale et al., 2018). In other words, the extended 'node-place-design' model can be understood as an analytical framework to evaluate TOD level of station areas concerning its 'transit', 'oriented' and 'development' aspects (Lyu et al., 2016).

Despite the benefits of the node-place-design model, current studies mainly focus on stations areas at the local level without a fuller consideration of the system level. Yet the TOD concept no longer remains at station catchment area at local scale, but extends to a broader geographical level. Explicitly, the salience of urban structure and organisation (polycentricism) principles are underscored in the content of networked TOD (Papa et al., 2013) in regional planning, with the aims of mitigating urban sprawl and boosting public transport patronage (Geurs et al., 2012, Papa and Bertolini, 2015).

Furthermore, Huang et al. (2018) argue that a transit node may have low performance at its individual level but serve an important role within the overall network. That is to say, adopting a transit network planning lens (Pan et al., 2017, Papa et al., 2013, Zhang and Goodrich, 2018, Huang et al., 2018) through which to study current classification models may provide more insights into understanding the TOD of metro station areas. 
Accordingly, the major aim of this paper is to extend the existing node-place-design approach by including a strategic network dimension and apply this to metro station areas' classification in Greater London. The remainder of this paper is organised as follows. Section 2 reviews the node-place model and its extended node-place-design model and introduces how the indicator of criticality can be combined with the node-place-design model to assess TOD performance of metro stations from a system perspective. Section 3 moves onto the application of the combination of node-place-design model and criticality in evaluating 270 metro station areas in Greater London. The final section draws conclusions on the significance of the findings in Greater London, reflects on possible improvements to the method, and discusses implications for future research and application on station area management and (re)development.

\section{Literature review}

\subsection{Node-place model and related studies}

The 'node-place model' introduced by Bertolini (1996) summarises a station area's characteristics with regard to two aspects, 'node' and 'place', denoted respectively on the y-axis and x-axis of a twodimensional diagram (Fig 1). The 'node' variable draws attention to the function of the station as a transport node, and measures the diversity and intensity of its transport function, which translates into the potential to promote physical and economic interaction. The 'place' variable considers the station as a site where people gather for extra-transport functions, and measures the diversity and intensity of activities found in a station. The balance between these two variables provides an indicator of the integration level of transport and other functions of a station. This sheds light on the opportunities and threats for redeveloping a station area to help reach an equilibrium in the "land use transport feedback cycle" (Giuliano, 2004, Meyer and Miller, 2001).

Based on node and place values, station areas can be classified into five typical categories. Those with coordinates along the diagonal line (stress area, balance area, and dependence area) are considered equally developed on the basis of a balanced development of both transport and land use. Conversely, stations located in the top left (unbalanced node area) and the bottom right (unbalanced place area) of the diagram are less balanced, leaning towards either their roles as node or place. Generally, stations located in the 'balance area' can be regarded as successful TOD, whereas stations located in the areas of 'unbalanced node' and 'unbalanced place' warrant attention and planning priorities or opportunities, indicating more development dynamics, either positive (upgrading) or negative (downgrading).

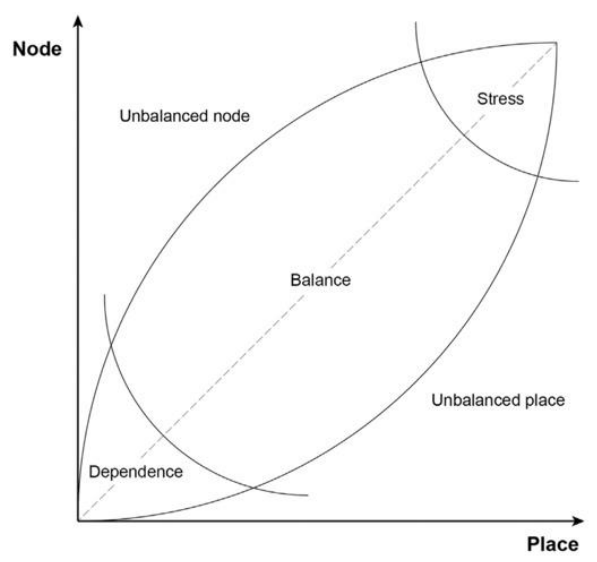

Fig. 1. The node-place model by Bertolini (1999).

Recent research on the node-place approach has provided greater sophistication in mainly three aspects, which are study area delineation, analytical index selection (Vale et al., 2018) and indicator enhancement. The first discussion is about the specification of TOD boundaries in practical analysis. Generally, an 800-m buffer ( 0.5 mile) is used for rail stations (Bernick and Cervero, 1997); a 400-m buffer ( 0.25 mile) is used for bus stops (Zhao et al., 2003). However, the selection of buffer radius varies in different contexts, for example, $3-\mathrm{km}$ is recommended for bicycle-based TOD in Seoul (Lee 
et al., 2016) and 500-m is used for Bus rapid transit (BRT) systems in the city of Bogotá (Cervero and Dai, 2014). While translating these knowledge into the node-place model, previous studies (e.g., Bertolini, 1999, Reusser et al., 2008) typically applied 700-metre straight line distance to generate catchment area around the railway stations. In recent years, some scholars (e.g., Vale et al., 2018, Lyu et al., 2016) tried to apply node-place model to metro station areas. To determine the reasonable service area radius for analysing metro stations under the node-place model, Vale and his colleagues (2018) revisited some studies (El-Geneidy et al., 2014, Jun et al., 2015) regarding station service threshold and applied 500-metre for Lisbon metro networks. In addition to applying service areas around stations, use of other study areas like census collection districts (Kamruzzaman et al., 2014), and whole urban areas (Papa and Bertolini, 2015) have shown positive results.

The second discussion pertains to extending the node-place model by adding a third dimension, design (Vale et al., 2018, Lyu et al., 2016). Vale (2015) firstly came up with the point that TOD classification of stations should be based on three different aspects: land use, transportation and walkability conditions. He suggested adding the human-oriented indicators like pedshed ratio to reflect the accessibility (walking condition) of station areas. Likewise, Lyu and his colleagues (2016) applied six design indicators like intersection density to reflect the accessibility of station areas. Two main ideas run through the reasoning of inclusion of this design dimension. First, the conventional node-place model could reflect the level of balance between land use and transport supply, but not the multiple dimensions of TOD. For example, in assessing the integration of land use and transport for Lisbon's metro network, Vale et al., (2018) found that a balanced station area is not necessarily a transit-oriented development, and vice versa. Some studies (Park et al., 2015, Sun et al., 2016, Cervero and Kockelman, 1997) have also revealed that, in addition to transport supply and land use characteristics, design characteristics like four-way intersection density have notably been associated with transit ridership. Second, Lyu and his colleagues (2016) highlighted the role of design in strengthening the realisation of the feedback cycle between transport and land use (Wegener and Fürst, 1999, Monajem and Nosratian, 2015). That is to say, over and above node and place, design should be regarded as the different dimension when evaluating TOD of station areas.

The third aspect is about indicators enhancement. Originally, Bertolini (1999) came up with fifteen indicators (nine for node, six for place) to assess a station area's node and place functionalities. An extensive amount of research followed, covering a wide range of node and place indicators, such as proximity to city centre (Chorus and Bertolini, 2011), public transport accessibility level (Kamruzzaman et al., 2014), and number of jobs (Zemp et al., 2011). Recent research put more focus on the discussion of walkability-related measures, such as pedshed ratio (Vale, 2015), cul-de-sac density (Kamruzzaman et al., 2014), connectivity (Van Nes and Stolk, 2012), intersection density, accessible network length (Vale et al., 2018, Lyu et al., 2016), and average block size (Lyu et al., 2016). A detailed discussion of indicators can be found in Lyu and his colleagues' work (2016).

\subsection{TOD and centrality of movement network}

As mentioned above, the recent discussion is mainly at local level around each station area per se. However, there is no consistent basis for understanding multiple roles of station areas, particularly the role stations play in urban polycentricity at regional level, whereas it has been found that providing land use and transport services requires long-term planning at both regional and local level (Kamruzzaman et al., 2014). Here the paper highlights the importance of adding system-wide centrality to the TOD evaluation. TOD's distinct emphasis is placed on different planning scales. In contrast to local planning focusing on the precise content of land use characteristics and their cooperation with transit, regional TOD planning centred on setting the spatial structure of TODs, e.g., hierarchical distribution of transport nodes, links and activities (Bossard et al., 2002). In other words, TOD not only offers the potential to create attractive station areas but also to shape polycentric cities and regions, mitigate urban sprawl and boost public transport ridership (Calthorpe and Fulton, 2001, Geurs et al., 2012, Leu et al., 2010). For instance, more compact urban structure can effectively 
produce less vehicle miles travelled (VMT) than sprawling development (Ewing et al., 2018; Ewing, 1997; Gordon \& Richardson, 1997). The TOD study in Arnhem-Nijmegen has found that some transit stations have distinct roles at local and regional levels due to various factors, e.g., station location within the urban structure and densities of urban functions (Huang et al., 2018). However, very few studies have included a regional TOD concept into transit classification. One exception is Papa et al. (2013), who identified seven typologies of stations areas drawing on network closeness and accessibility in the Randstad area.

Nevertheless, existing studies lack a distinct strategic network component. As Doursat (2005) argued, '[n]etwork analysis is crucial to characterise because structure affects function and vice-versa'.

Research using a network approach with functional flow data (e.g., numbers of passenger and mobile phone data) does not have a long history, largely because network science has only recently been extended to apply with spatial networks (Barthelemy, 2016, Barthélemy, 2011). Grounded in the functional understanding of the urban spatial structure, the network-based approach delineates the spatial interactions among communities through extracting the characteristics of the urban socioeconomic associations networks (Chowell et al., 2003, McMillen, 2001), which sheds lights on deciphering the organisations and hierarchical relations between sub-regions. For example, Zhong et al. (2014) found that smart card data is an efficient proxy in exploring the urban organisations in detecting the variations of urban structure in Singapore. Roth et al., (2011) identified multiple centres and ranked London stations areas hierarchically through analysing the passenger flow data. The fundamental idea is to use the individual movement data as a proxy to reveal the structure and organisation of the city. As one of the most fundamental measures, network centrality has been used for detecting hierarchical spatial organisation (Piovani et al., 2017) and functional centres (Li and Phelps, 2018). A number of empirical studies have found that functional network centrality can effectively capture location advantage in a city and reflect intra-urban variation of land use and transport intensity and hierarchy (Roth et al., 2011, Wang et al., 2014). Therefore, we introduce a strategic network (criticality) component to enhance the value of the node-place design approach.

\section{Method}

We illustrate our approach with a case study of the Greater London's metro system. As shown in Figure 2, the London metro network is composed of eleven lines running across $402 \mathrm{~km}$ and serving 270 stations. The four data sets (Table 1) used in the node-place-design analysis are: 1) British-isles Shapefile from OpenStreetMap (OSM) which contains the street network, Point of Interests (POI), transport and traffic layers, etc. (downloadable from: http://download.geofabrik.de/europe/britishisles.html), 2) National Public Transport Access Nodes (NaPTAN) from Department for Transport (DfT) (downloadable from: http://data.gov.uk/dataset/nptdr), 3) the 2011 Census data on Lower Super Output Area (LSOA) scale from Office for National Statistics (ONS) (downloadable from: https://www.ons.gov.uk/census) and 4) metro timetable data from TfL (downloadable from http://timetables.data.tfl.gov.uk/). Based on the passenger flow data and the spatial relation of each station, an undirected weighted graph is constructed to represent the overall travel on every pair of links in the city during the workdays. Formally, the network can be defined as an undirected weighted graph as $\mathrm{G}=(\mathrm{N}, \mathrm{L}, \mathrm{W})$, where $\mathrm{N}$ refers to the number of metro stations, $\mathrm{L}$ represents the number of links, and $\mathrm{W}$ indicates the Euclidean distance of each link respectively. In the case of London, the values for $\mathrm{N}$ and $\mathrm{L}$ are 270 and 372 respectively. 


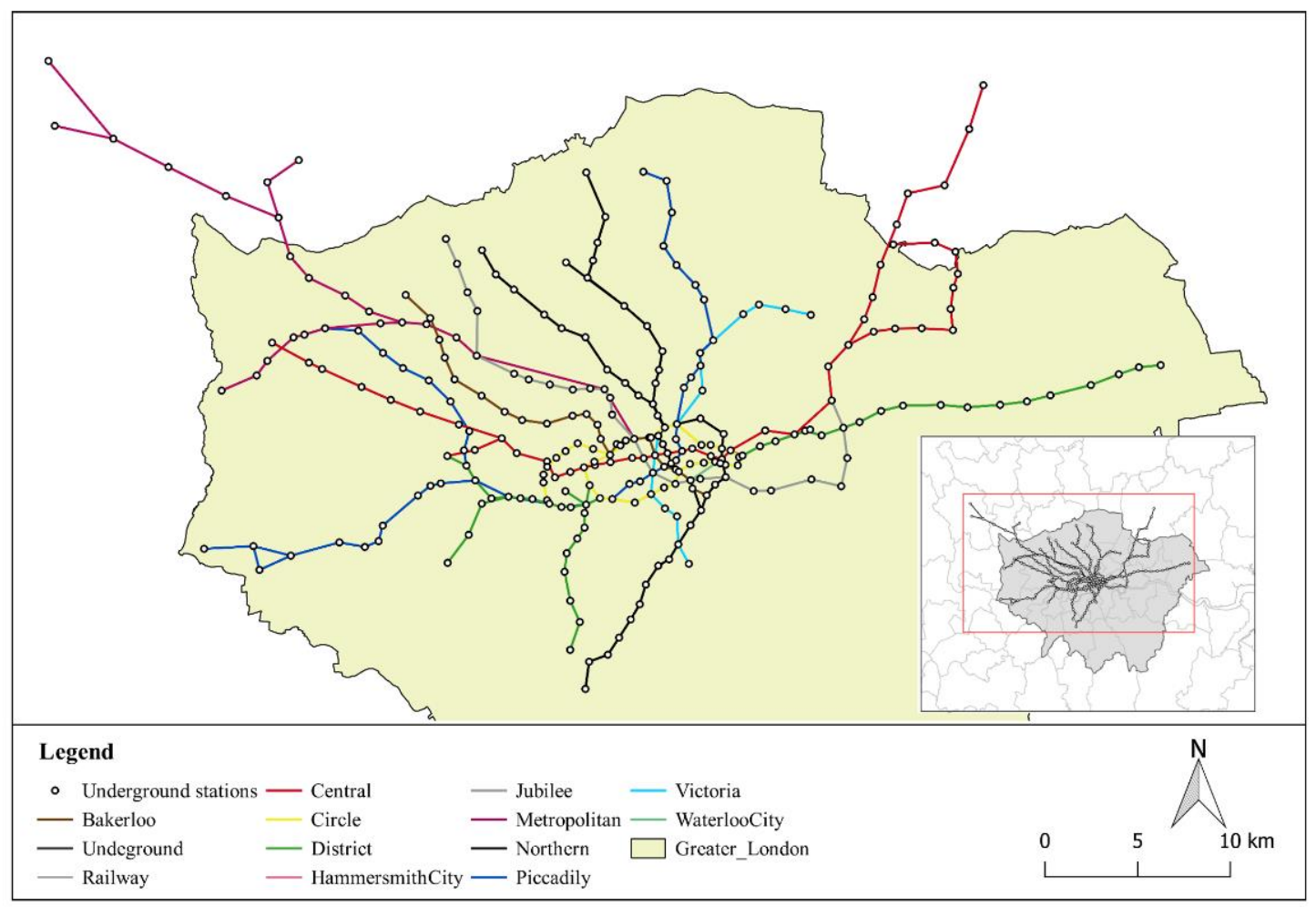

Fig. 2. Location of metro stations of Greater London.

In line with Vale et al. (2018), our method is based on fourteen indicators (Table 1): seven for the node index, four for the place index, and three to measure the design of the metro station areas. All variables are collected from the catchment areas with $960 \mathrm{~m}$ radius and checked for normality. The selection of this radius is because we assume that people will walk up to 960 metres (12 minutes) to metro services (TfL, 2015). Following McCune and Grace (2002), all indicators are log transformed based on $\log (x+1)$ because if the lowest nonzero value in the data is one then it is best to add one before applying the transformation. The collinearity examination is conducted before data processing. The statistical literature (Douglass et al., 2003, Belsley, 1991) provides several quantifications of collinearity, with the most recurring being the correlation coefficient (r). Here the study draws on the critical value 0.7 as the threshold (Dormann et al., 2013) to detect the dependence of measures. If there is collinearity between indicators, principal component analysis (PCA) will be conducted to reduce collinearity among variables. Because PCA is a variable reduction procedure that uses an orthogonal transformation to convert a set of observations of possibly correlated variables into a set of values of linearly uncorrelated variables (Jolliffe,1986, Dormann et al., 2013). Not only can this approach indicate the contribution of each indicator, but it also reduces the collinearity among indicators. 
Table 1

Indicators used to measure node, place and design index (with data sources).

Indicator description Calculation

\section{Node index}

Number of directions served by metro

(NaPTAN:DfT)

Daily frequency of metro services (timetable: TfL)

Number of stations within 20min of travel (NaPTAN:DfT)

Number of directions served by other public transport (bus, train and tram) (NaPTAN:

DfT)

Daily frequency of services by other public transport (NaPTAN:DfT)

Distance from the closest motorway access

Number of car parking spaces (extracted from OSM)

\section{Place index}

Number of residents (Census: ONS)

Number of workers (Census: ONS)

Land use mix (OSM)

Number of POIs (OSM)

\section{Design index}

Pedshed ratio (OSM)

Intersection density(OSM)

Accessible network length (OSM)

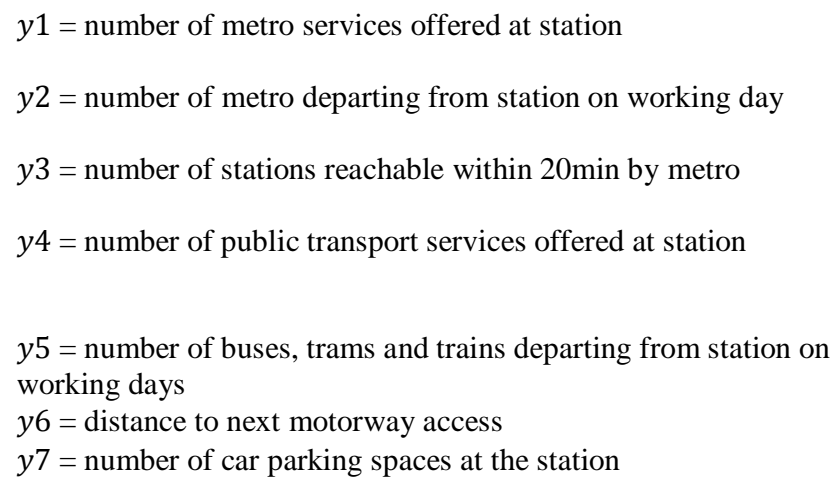

$x 1=$ number of residents within $960 \mathrm{~m}$ $x 2=$ number of employments within $960 \mathrm{~m}$ $x 3=-\sum_{j} \frac{P_{j} \times \ln \left(P_{j}\right)}{\ln (\mathrm{J})}$, where $P_{j}$ is the proportion of developed land in the $j$ th use type. This is based on a measure of entropy firstly used by Cervero (1989).

$x 4=$ number of points of interest (POIs) within $960 \mathrm{~m}$

$$
\begin{aligned}
& w 1=\text { pedestrian shed ratio, see Vale et al (2015). } \\
& w 2=\text { density of intersections per hectare } \\
& w 3=\text { length of the accessible network (metres) }
\end{aligned}
$$

Cluster analysis is then applied to obtain classes of London metro stations with minimal variance within the group and maximal variance between each other. K-means cluster analysis is performed here. The optimal number of clusters is calculated with average silhouette method (Rousseeuw, 1987). The conventional approach would stop at here and make suggestions for station area management. However, what is not yet clear is the role station serves at the strategic network level. In parallel to cluster analysis, we add the criticality analysis of each station, in order to illuminate the variations between stations within the same clusters and identify the strategic importance of each station area Explicitly, to gain deeper insight into station areas, our analysis is based on their node-place-design performance at the local level and importance in urban structure at the system level. One point to note here is that some studies (e.g. Caset et al., 2018) included centrality indicators such as betweenness and closeness into the nodal aspect, but those network indicators are calculated based on the features of transit infrastructure network instead of the passengers' movement network. Drawing on the 2017 Rolling Origin \& Destination Survey (RODS) data from TfL (https://tfl.gov.uk/info-for/open-datausers/our-open-data?intcmp=3671), the movement network is constructed. This dataset contains the Oyster Origin and Destination flows of stations within the overall London metro network encompassing averagely a total of 4.88 million journeys per weekday in 2017 . We use a weighted betweenness centrality as an index to identify the relative positioning of local areas in the more global spatial structure and measure how well-connected an area is (Zhong et al., 2014). As found in Iyer et al.'s (2013) work, the betweenness centrality can better identify the most critical stations compared to other centrality algorithms. The index is defined as the number of shortest paths passing through a vertex, where consider paths between all connected vertex pairs (Newman, 2010, Barabási, 2016). As shown in equation (1), the betweenness centrality of a node $k$ is the number of shortest paths connecting any two areas (nodes) $i$ and $j$ in the graph that pass through the node $k$. The greater the 
number of the shortest paths traversing it, the higher centrality a node will be. This relation is defined as follows:

$$
C_{\text {betweenness }}(k)=\sum_{i j} \frac{\delta_{i j}(k)}{\delta_{i j}}
$$

Where $\delta_{i j}(k)$ is the number of shortest paths between any two nodes $i$ and $j$, that passes through $\mathrm{k}$, and $\delta_{i j}$ is the number of total paths between $i$ and $j$. The weighted centrality is calculated on the RStudio platform using igraph package (http://igraph.org).

\section{Results}

\subsection{The node-place-design model for Greater London}

As mentioned in previous section, collinearity diagnostics is conducted firstly. Supplement A shows there is a significant dependence according to Pearson's $r$ correlation coefficient, particularly among design and place measures. This finding confirms the need to adopt an extended approach to recalculate the weights of each indicator. Here, we use PCA to extract node, place and design indices. Table 2 reports eigenvalues and eigenvectors of factors, and summarises statistics of the variables of the final node-place-design indices. The study follows the Kaiser-Guttman rule (1960) and selects only one component (with an eigenvalue greater than one) to generate node-place-design indices.

Table 2

Principal component analysis for factors contributing to node-place-design indices

\begin{tabular}{llll}
\hline & \multicolumn{3}{c}{ Eigenvectors } \\
\cline { 2 - 4 } Factors & V1 & V2 & V3 \\
\hline$y$ 1: Number of directions served by metro & 0.750 & 0.130 & 0.083 \\
2: Daily frequency of metro services & 0.453 & 0.452 & 0.790 \\
y3: Number of stations within 20min of travel & 0.762 & 0.132 & 0.564 \\
y4: Number of directions served by other public & 0.531 & 0.059 & 0.485 \\
transport & & & \\
y5: Daily frequency of services by other public & 0.478 & 0.278 & 0.392 \\
transport & & & \\
$y$ 6: Distance from the closest motorways access & 0.120 & -0.570 & 0.423 \\
$y$ 7: Number of car parking spaces & 0.090 & 0.001 & 0.002 \\
Eigenvalue (node) & 3.210 & 0.798 & 0.209 \\
Proportion of variance explained (\%) & 71 & 27 & 3 \\
& & & \\
\hline$x$ 1:Number of residents & 0.632 & 0.020 & 0.130 \\
$x$ 2: Number of workers & 0.214 & 0.137 & -0.020 \\
$x$ 3: Land use mix & 0.793 & -0.360 & 0.089 \\
$x$ 4: Number of POIs & 0.733 & -0.260 & 0.030 \\
Eigenvalue (place) & 2.601 & 0.870 & 0.218 \\
Proportion of variance explained (\%) & 74 & 23 & 3 \\
& & & \\
\hline w1: Pedshed ratio & 0.332 & 0.694 & 0.000 \\
w2: Intersection density & 0.697 & -0.190 & 0.040 \\
w3: Accessible network length & 0.697 & -.0190 & -0.400 \\
Eigenvalue (design) & 2.020 & 0.630 & 0.100 \\
Proportion of variance explained (\%) & 69 & 30 & 1 \\
& & & \\
\hline
\end{tabular}

K-means cluster analysis is then applied among node, place and design combined indices. The number of clusters is chosen as five because at this number the average silhouette value reaches its peak of 0.5. Of the five clusters (see Table 3, Fig.3), Cluster 1 (the number of station areas $=50$ ), located in the core of urban areas, particularly concentrates within central London. One exception is Canary Wharf Station which is far away from city centre but still has high score of node, place, and design value $(0.75,0.85$, and 0.64$)$. This 'discrepancy' may be attributed to its special role in strategic planning: the Canary Wharf area was deliberately planned to be in effect a new Central Business District for London; and contains many financial institutions and thus has a great intensity and 
diversity of the land use. Besides the conventional surface streets, the fact that Canary Wharf has a well-developed and connected network of underground roads could also lead to some inaccuracy to the design score. As shown in table 2, the average of place and design scores are lower than nodes within Cluster 1 station areas, such as Bank Station (0.93, 0.94, and 0.98). Nevertheless, it does not mean all stations within Cluster 1 follow this trend. For example, Waterloo Station has higher node score (0.99), and lower place (0.81) and design (0.80) scores. Similarly, though with a node value of 0.96, King's Cross Station achieves only 0.73 and 0.77 for its place and design values.

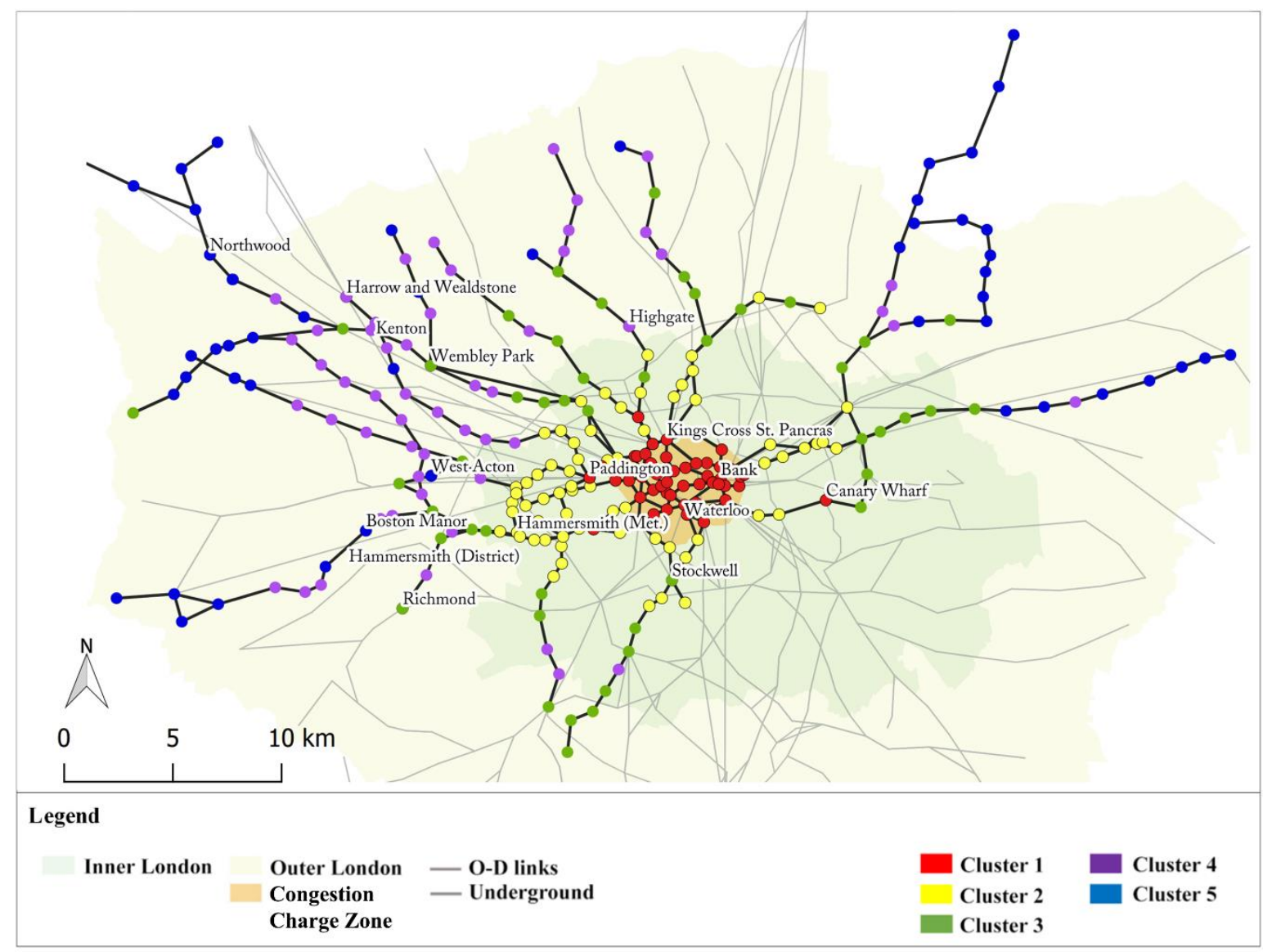

Fig. 3. The classification of metro station areas in Greater London based on node-place-design principal components.

Table 3

Cluster description summary.

\begin{tabular}{|c|c|c|c|c|c|c|}
\hline Clusters & $\begin{array}{l}\text { Number } \\
\text { of stations }\end{array}$ & Example of stations & $\begin{array}{l}\text { Avg. } \\
\text { node }\end{array}$ & $\begin{array}{l}\text { Avg. } \\
\text { place }\end{array}$ & $\begin{array}{l}\text { Avg. } \\
\text { design }\end{array}$ & $\begin{array}{l}\text { Avg. } \\
n-p-d\end{array}$ \\
\hline $\mathrm{C} 1$ & 50 & $\begin{array}{l}\text { Paddington, Piccadilly Circus, } \\
\text { Waterloo, Canary Wharf, Liverpool } \\
\text { St, Aldgate, Angel }\end{array}$ & 0.789 & 0.875 & 0.807 & 0.824 \\
\hline $\mathrm{C} 2$ & 67 & $\begin{array}{l}\text { Hammersmith, West Kensington, } \\
\text { Bow Church }\end{array}$ & 0.599 & 0.654 & 0.581 & 0.611 \\
\hline $\mathrm{C} 3$ & 47 & $\begin{array}{l}\text { Acton Town, Hampstead, Richmond, } \\
\text { Wembley Park }\end{array}$ & 0.573 & 0.492 & 0.381 & 0.482 \\
\hline $\mathrm{C} 4$ & 54 & $\begin{array}{l}\text { Highgate, Harrow and Wealdstone, } \\
\text { Kenton }\end{array}$ & 0.421 & 0.388 & 0.279 & 0.362 \\
\hline C5 & 52 & $\begin{array}{l}\text { West Acton, North Wood, Boston } \\
\text { Manor }\end{array}$ & 0.331 & 0.201 & 0.148 & 0.227 \\
\hline
\end{tabular}


Cluster 2 (the number of station areas $=67$ ) and Cluster 3 (the number of station areas $=47$ ) are mostly located in Inner London. Although stations in both clusters have high values for the node indicator, there are some notable differences. The place and design scores of Cluster 2 are much higher than Cluster 3, which indicates that Cluster 2 stations areas are more walkable, with high clustering of jobs and residences around the stations. On the other hand, station areas in Cluster 3 show relatively high score for node but low score for place and design. One possible explanation for this might be that these stations are taking on more transfer tasks. One typical case is Stockwell Station: its node, place and design values are separately $0.69,0.58$ and 0.42 . Since the station lies at the intersection of Northern Line and Victoria Line, the node value is supposed to be higher than the local transport demand and also relatively higher than place and design values.

Cluster 5 (the number of station areas $=52$ ), located in the periphery of the urban area and the suburban branches of the metro system, comprises the station areas with the lowest value of node, place and design. Compared to Cluster 5, Cluster 4 (the number of station areas $=54$ ) score higher on distance to jobs and residences with higher design value. With regards to spatial distribution, most station areas in Cluster 4 and Cluster 5 are located in Outer London, but station areas in Cluster 4 are relatively closer to Inner London with higher value of design and place.

Besides classifying all station areas into five clusters, we also analyse the relation between each component. As shown in Figure 4, Greater London metro station areas exhibit a general balance between node, place and design indices, despite certain exceptions. Generally, the node, place and design indices exhibit the similar trend: there is a positive relation between node and place $\left(\mathrm{R}^{2}=\right.$ $0.699)$, and there is a strong correlation between place and design $\left(R^{2}=0.805\right)$, which indicates that the accessibility of metro stations has been incorporated into land use patterns. The result of a relatively low correlation $\left(\mathrm{R}^{2}=0.604\right)$ between node and design indices is consistent with Vale's (2015) finding that a high node value does not necessarily means the station's surrounding areas are well designed, confirming that it is important to include design index into assessment to improve our understanding of metro stations (Vale et al., 2018). For example, Victoria (node $=0.94$, design $=0.65$ ) and Elephant and Castle (node $=0.89$, design $=0.69$ ) are the stations which have high node value performance but relatively inaccessible walking environment. It is hardly surprising that this result is coherent with TfL's current station upgrade decision; the core aim of ongoing upgrade projects is to make passengers' access easier and safer. 


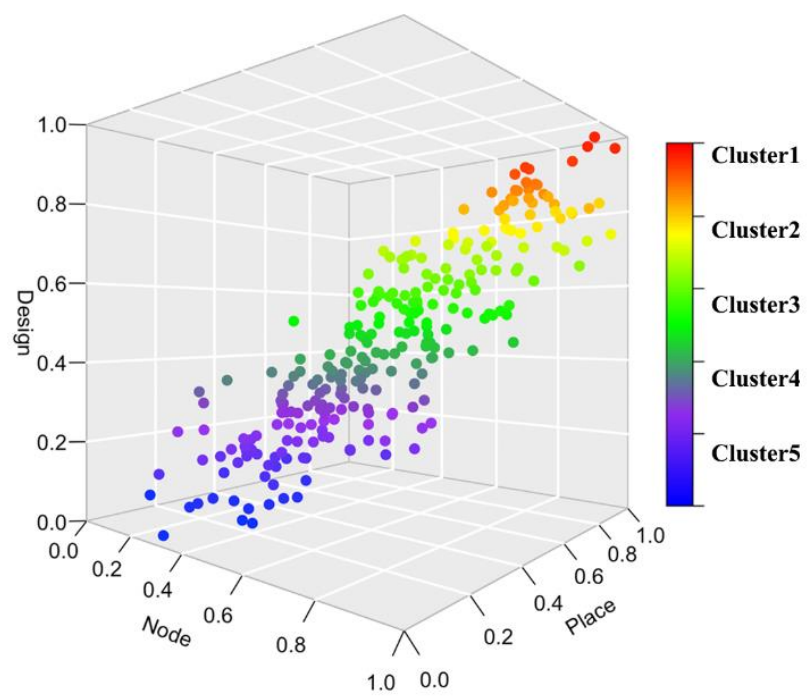

(a) Scatter plot of node, place and design

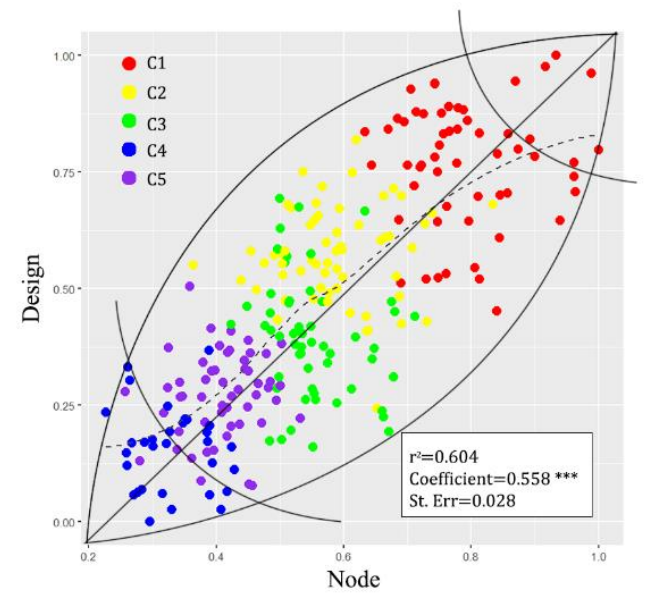

(c) Scatter plot of node and design

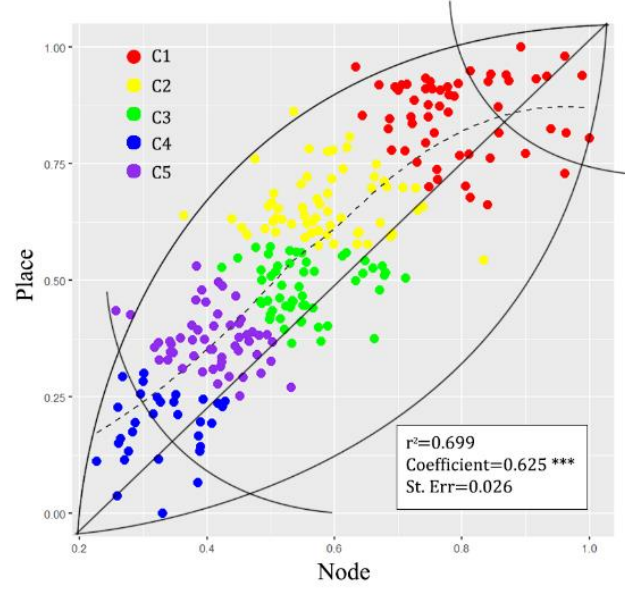

(b) Scatter plot of node and place

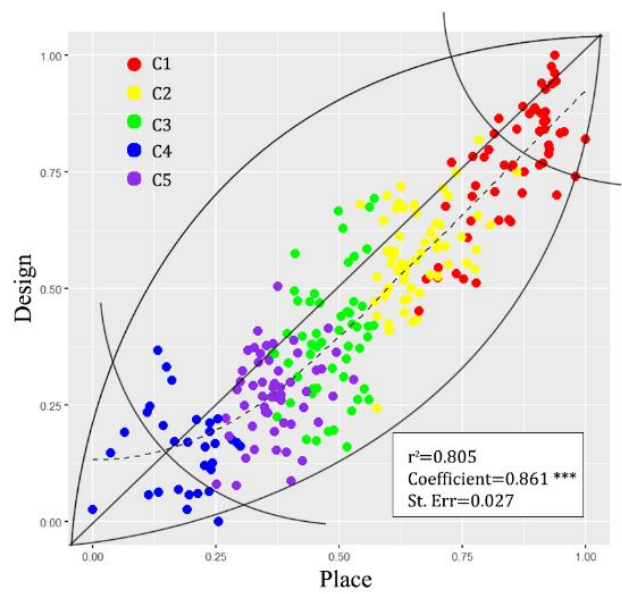

(d) Scatter plot of place and design

Fig. 4. Scatter plot of London metro stations in the node-place-design model from a synthetic and three paired perspectives.

\subsection{The node-place-design model and network criticality for Greater London}

While the node-place-design analysis provides us with a lens to classify station areas into groups according to the level of integration of transport, land use and walking environment, stations within the same group still vary significantly in terms of their importance to the whole urban structure at regional scale. Network centrality analysis (Supplement B) is adopted here to measure the role stations play at a system level. As shown in Figure 5, stations with high criticality value (represented by larger dots) are generally located in central London. An interesting finding is that these metro stations with high criticality values (e.g. King's Cross, Liverpool Street, Waterloo, Paddington, Victoria station) are co-located with railway stations, even though their criticality values are computed based on the metro network only. This phenomenon probably is the result of interaction of the two systems (metro and rail).

The other finding is that the criticality of stations within the same cluster varies a lot. The most distinguishing difference can be identified within Cluster 1 (and indeed one could consider subdividing clusters to reflect these differences). As shown in Figure 6, both Aldgate and Liverpool Street stations are in Cluster 1, and they have roughly similar node-place-design values $(0.87$ and 0.93 
respectively) as they are close geographically; however their normalised criticality values are very different ( 0.06 and 0.96 respectively) because Aldgate is only served by the Circle and Metropolitan lines, while Liverpool Street also interchanges with the Central and Hammersmith and City lines. To some extent, this shows that the two-tier approach can contribute to gaining understanding of diverse roles of stations at both local and system levels, especially in the case of identifying stations with great development potential or future adaption to guide investment and strategic planning.

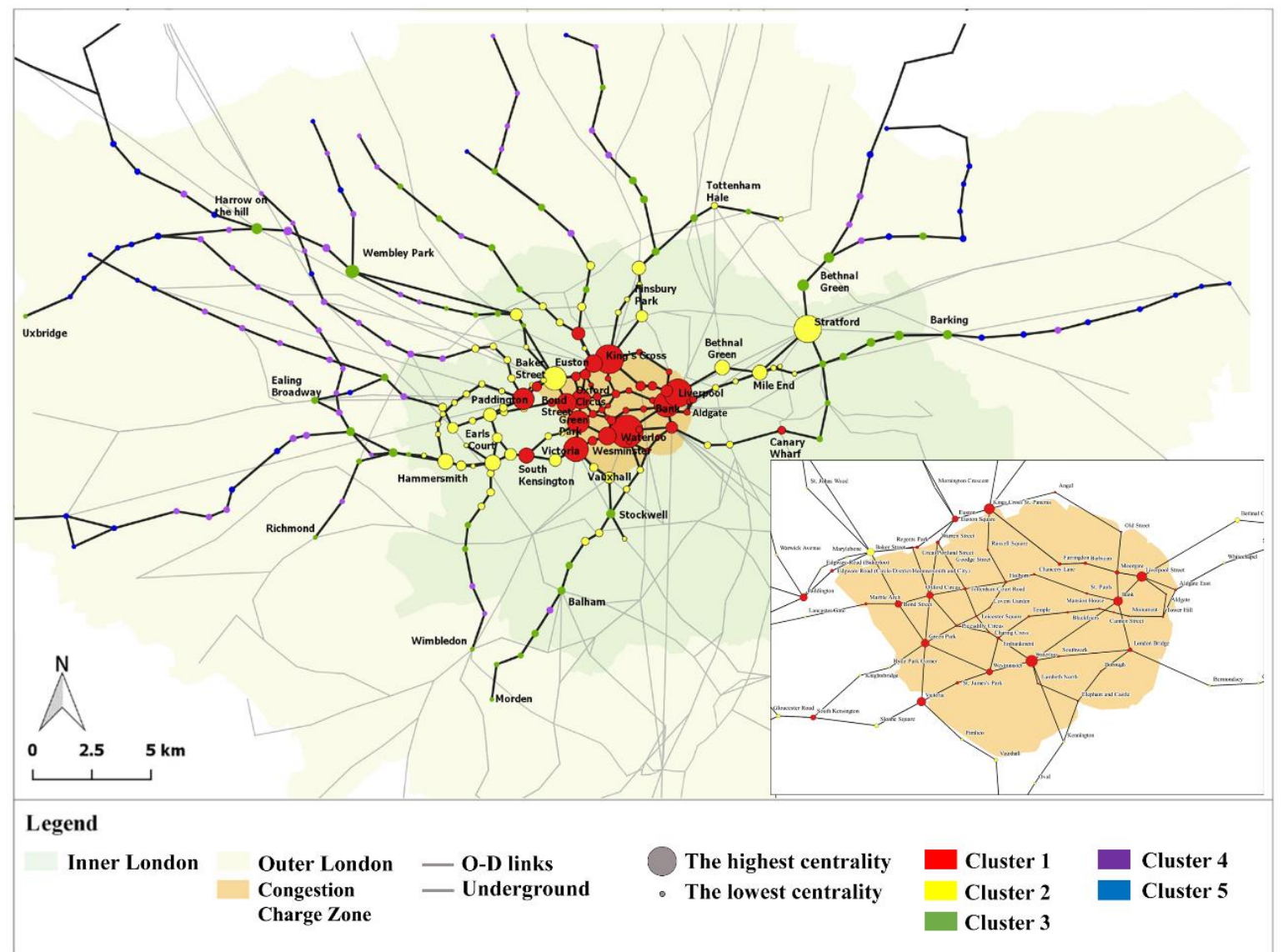

Fig. 5. The classification of metro station areas in Greater London based on the combination of criticality and node-placedesign model (each station is represented by a dot, whose colour indicates the station's corresponding cluster, and whose size indicates the station's criticality level in the system).
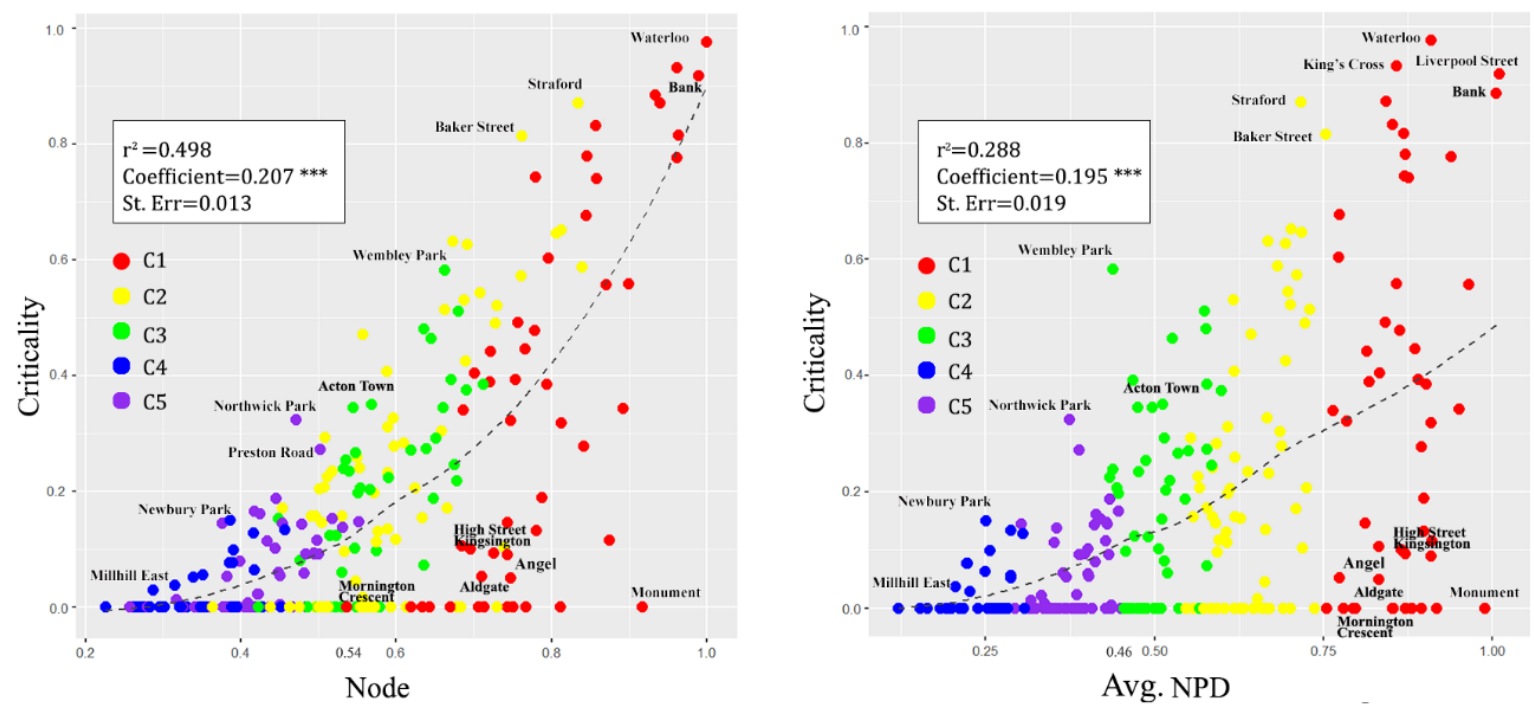

Fig. 6. Scatter plot of node-criticality and NPD-criticality. 
The study also identifies an intensification-diversification TOD group. Station areas in this group are featuring with modest or relatively low node-design-place scores and relatively high score of criticality, e.g., Wembley Park, Acton Town, and Harrow on the Hill, Stockwell, Barking, and Northfields. This suggests directing attention to these locations for potential future (re)development due to two considerations. First, this group are crucial to ensure the overall function of the transport system. As shown in Figure 5, they are either located at the intersections of several metro lines or railway lines, or close to some very critical stations. These station areas are the alternative stations for passengers to choose when their surrounding station disrupts, such as closure; or on the other hand, the disruption of these stations such as due to delay may cause more negative impacts on the whole system, as its malfunction can affect multiple lines of the metro system (Albert et al., 2000). Second, from a strategic perspective, these station areas have potential for further development as sub-centres. Furthermore, the relatively low node-design-place values indicate that there can possibly be greater potential to diversify and intensify station areas in terms of transport, land use and walking environment aspects. These areas can be ideal places to accommodate the new wave of population growth in London.

In contrast to these easily ignored stations, there are also stations, which have high node-place-design value but low criticality scores, e.g., St. Pauls, High Street Kensington, Mornington Crescent, Old Street and Angel. The moderately or very low criticality here indicates they are playing relatively less important roles at the system level, but more important roles at local level. For example, Angel station is not an interchange station; it has a low criticality value but it is located at a vibrant sub-centre, and the focal point in the local road and pedestrian network. Such stations could be considered candidates for new network interventions such as new lines or interchanges. Indeed, Angel is due to become a new interchange station with the proposed Crossrail 2 line, and our analysis could be seen to retrospectively corroborate the value of doing so. This logic also suggests the potential for identifying locations in other cities where new lines or interchanges could advantageously be introduced.

\section{Discussion and Conclusions}

This paper gives an example of the potential contribution of network analysis in assessing how well station areas are aligned with the goal of transit-oriented development. This approach expands on and complements the node-place-design model in conjunction with criticality assessment to analyse the performance of Greater London metro station areas at both local and system levels. This study has three key findings. First, the analysis shows that station areas in Greater London generally have good integration of transport, land use and walking environment. It can therefore be assumed that planners have already taken the TOD principles into account in planning. However, some station areas need more attention in future management, such as station areas with less walking-friendly environment, e.g., Victoria and Elephant and Castle stations. Second, this study finds that there are significant discrepancies of criticality of station areas within the same cluster, particularly station areas in Cluster 1. This is largely due to various roles they play in the network structure at regional level. Third, while the correlation analysis reveals that there are positive associations between any pair of node, place and design indices, the relatively low correlation between node and design values in this study corroborates previous findings of Vale et al. (2018) that a high-performance node does not necessarily have a walking friendly station area.

Our empirical results provide some policy implications. Generally, we suggest policymakers and planners consider both the local and system level when performing TOD assessment of station areas, that is, bringing a strategic network dimension into TOD planning. The two-tier approach could help them identify potential TOD stations which are worth considering for intervention. Stations with relatively high system criticality and relatively low node-place-design value (such as Wembley Park) could be worthy of attention as potential candidates for encouraging densification and diversification to increase the land use efficiency and thereby accommodate the urban growth. In addition, the scalecombined perspective shows that there is no "one-size-fits-all" solution to promote TOD. Station areas with similar NPD may need different development policy given their multiple roles at both local and regional levels. For example, both King's Cross St Pancras station and Canary Wharf stations are 
classified into the first group (C1) according to node-place-design model, but their distinct contribution to the system function can illuminate variations between stations explicitly. Our results also find that some stations with high node values and low place-design values, concentrated mostly in Cluster 3, could be promising areas for implementing land value-capture. For instance, owing to the existing advantage of transport connection and proximity to the city centre, Cluster 3 station areas would seem to be potential candidates for London's Land Use Capture Project (GLA, 2017), a joint venture of Greater London Authority (GLA) and TfL which aims at using a set of mechanisms to monetise increases in land values that arise in the catchment areas of transport projects.

The framework could also assist with future metro or rail system planning, for example, in directing attention to where new lines, stations or interchanges could be considered, echoing the example of Angel, which has a high node-place-design value but low network criticality.

We recognise some limitations in our results, and areas for further development. First, we give little consideration of the context-specific node, place and design indicators. Local expert questionnaires and repertory grid interview suggested by Ressuer et al. (2008) could be conducted to lend weight to indicator selection for the case of Greater London metro station areas. Second, boundaries selection (e.g., the shape and catchment radius of station areas) can to some extent affect the results, especially when defining the different catchment radii for the stations within Inner London and Outer London. Future research therefore could focus on doing comparative study to examine to what extent the modifiable area unit problem (MAUP) of catchment selection may affect station areas classification. Third, although PCA offers us a tool to reduce the redundancy of indicators, it also introduces certain biases. For example, the analysis procedure is sensitive to the scaling which requires more delicate approach to processing, and the key components can not fully represent the original variance. These limitations could be addressed in further studies. Fourthly, further work could be done to identify further clustering (sub)divisions (e.g. dividing Cluster 1 into high and low criticality sub-clusters).

Finally, we suggest that the extended model could be further developed to include (i) an additional indicator to capture the relative local centrality of a station's position in its local street network (as a measure of local network orientation to the station, to complement design indicators); and (ii) additional strategic network indicators (e.g. more centrality indicators should be included to examine their effectiveness on reflecting criticality at the system scale). Indeed the strategic network dimension could potentially become a distinct fourth dimension in addition to node, place and design in future analyses. This agenda could strengthen both local and strategic aspects of TOD from a network perspective, suggesting both where to target attention to development relative to transit, and transit relative to development.

\section{References}

1. Albert, R., Jeong, H. \& Barabási, A. L. 2000. Error and attack tolerance of complex networks. Nature, 406, 378-382.

2. Barabási, A. L. 2016. Network science, Cambridge university press. Cambridge University Press.

3. Barthélemy, M. 2016. The Structure and dynamics of cities, Cambridge University Press.

4. Barthélemy, M. 2011. Spatial networks. Physics Reports, 499, 1-101.

5. Belsley, D. A. 1991. A guide to using the collinearity diagnostics. Computer Science in Economics and Management, 4(1), pp. 33-50.

6. Bernick, M., Cervero, R. 1997.Transit Villages in the 21st Century. NewYork: McGraw-Hill.

7. Bertolini, L. 1996. Nodes and places: complexities of railway station redevelopment. European Planning Studies, 4, 331-345.

8. Bertolini, L. 1999. Spatial development patterns and public transport: the application of an analytical model in the Netherlands. Planning Practice and Research, 14, 199-210. 
9. Bossard, E. G., Hobbs, J., Hondorp, B., Kelly, T., Plembaeck, S., Salazar, D., Subotic, A., Taketa, R., Tran, T. \& Wang, P. Y. 2002. Envisioning neighborhoods with transit-oriented development potential. Mineta Transportation Institute. MTI Report 01-15.

10. Calthorpe, P. 1993. The next American metropolis: Ecology, community, and the American dream, Princeton architectural press. Princeton, NJ.

11. Calthorpe, P., \& Fulton, W. (2001). The regional city. Island Press.

12. Caset, F., Vale, D. S. \& Viana, C. M. 2018. Measuring the accessibility of railway stations in the Brussels Regional Express Network: a node-place modeling approach. Networks and Spatial Economics, 18(3),495530 .

13. Cervero, R. 1989. Land-use mixing and suburban mobility. Transportation Quarterly, 42, 429-446.

14. Cervero, R., 2007. Transit-oriented development's ridership bonus: a product of self-selection and public policies. Environment and planning A, 39(9), pp.2068-2085.

15. Cervero, R. and Dai, D., 2014. BRT TOD: Leveraging transit oriented development with bus rapid transit investments. Transport Policy, 36, pp.127-138.

16. Cervero, R. \& Kockelman, K. 1997. Travel demand and the 3Ds: density, diversity, and design. Transportation Research Part D: Transport and Environment, 2, 199-219.

17. Chorus, P. \& Bertolini, L. 2011. An application of the node place model to explore the spatial development dynamics of station areas in Tokyo. Journal of transport and land use, 4(1), 45-58.

18. Chowell, G., Hyman, J. M., Eubank, S. \& Castillo-Chavez, C. 2003. Scaling laws for the movement of people between locations in a large city. Physical Review E, 68 (2), 1855-1862.

19. Conticelli, E. 2011. Assessing the potential of railway station redevelopment in urban regeneration policies: an Italian case study. Procedia Eng, 21, 1096-1103.

20. Dittmar, H. \& Ohland, G. 2012. The new transit town: best practices in transit-oriented development, Island Press, Washington.

21. Dormann, C. F., Elith, J., Bacher, S., Buchmann, C., Carl, G., Carré, G., Marquéz, J. R. G., Gruber, B., Lafourcade, B. \& Leitão, P. J. 2013. Collinearity: a review of methods to deal with it and a simulation study evaluating their performance. Ecography, 36, 27-46.

22. Douglass, D. H., Clader, B. D., Christy, J. R., Michaels, P. J. \& Belsley, D. A. 2003. Test for harmful collinearity among predictor variables used in modeling global temperature. Climate research, 24, 15-18.

23. Doursat, R., 2005. Topology and Dynamics of Complex Networks. Seminar Modelling \& Simulation Department of Computer Science \& Engineering. Department of Computer Science \& Engineering University of Nevada, Reno, Spring.

24. El-Geneidy, A., Grimsrud, M., Wasfi, R., Tétreault, P. \& Surprenant-Legault, J. 2014. New evidence on walking distances to transit stops: identifying redundancies and gaps using variable service areas. Transportation, 41, 193-210.

25. Ewing, R., 1997. Is Los Angeles-style sprawl desirable? Journal of the American planning association, 63(1), pp.107-126.

26. Ewing, R., Tian, G. and Lyons, T., 2018. Does compact development increase or reduce traffic congestion? Cities, 72, pp.94-101.

27. Ewing, R. \& Cervero, R. 2001. Travel and the built environment: a synthesis. Transportation Research Record: Journal of the Transportation Research Board, 87-114.

28. Geurs, K. T., Krizek, K. J. \& Reggiani, A. 2012. Accessibility analysis and transport planning: challenges for Europe and North America, Edward Elgar Publishing, Northampton, USA.

29. Giuliano, G. 2004. Land use impacts of transportation investments. The geography of urban transportation, 3, 237-273.

30. Gordon, P. and Richardson, H.W., 1997. Are compact cities a desirable planning goal? Journal of the American planning association, 63(1), pp.95-106.

31. Greater London Authority (GLA). 2017. Land Use Capture. London: Greater London Authority.

32. Greater London Authority (GLA). 2018. Lonodn Plan. London: Greater London Authority.

33. Higgins, C. D. \& Kanaroglou, P. S. 2016. A latent class method for classifying and evaluating the performance of station area transit-oriented development in the Toronto region. Journal of Transport Geography, 52, 61-72. 
34. Huang, R., Grigolon, A., Madureira, M. \& Brussel, M. 2018. Measuring transit-oriented development (TOD) network complementarity based on TOD node typology. Journal of transport and land use, 11, 304-324.

35. Iyer, S., Killingback, T., Sundaram, B. \& Wang, Z. 2013. Attack robustness and centrality of complex networks. PloS one, 8, e59613.

36. Jolliffe, I. 1986. Principal component analysis, Springer, New York.

37. Jun, M.J., Choi, K., Jeong, J. E., Kwon, K. H. \& Kim, H. J. 2015. Land use characteristics of subway catchment areas and their influence on subway ridership in Seoul. Journal of Transport Geography, 48, 30-40.

38. Kaiser, H. F. 1960. The application of electronic computers to factor analysis. Educational and psychological measurement, 20, 141-151.

39. Kamruzaman, M., Baker, D., Washington, S. \& Turrell, G. 2014. Advance transit oriented development typology: case study in Brisbane, Australia. Journal of Transport Geography, 34, 54-70.

40. Lee, J., Choi, K. and Leem, Y., 2016. Bicycle-based transit-oriented development as an alternative to overcome the criticisms of the conventional transit-oriented development. International Journal of Sustainable Transportation, 10(10), pp.975-984.

41. Leu, G., Abbass, H. \& Curtis, N. 2010. Resilience of ground transportation networks: a case study on Melbourne. Australasian Transport Research Forum (ATRF), 33rd, 2010, Canberra, ACT, Australia.

42. Li, Y. \& Phelps, N. 2018. Megalopolis unbound: Knowledge collaboration and functional polycentricity within and beyond the Yangtze River Delta Region in China, 2014. Urban Studies, 55, 443-460.

43. Lund, H. M., Cervero, R. \& Willson, R. 2004. Travel characteristics of transit-oriented development in California. Sacramento, CA: California Department of Transportation.

44. Lyu, G., Bertolini, L. \& Pfeffer, K. 2016. Developing a TOD typology for Beijing metro station areas. Journal of Transport Geography, 55, 40-50.

45. Mccune, B. \& Grace, J. 2002. Analysis of ecological communities-MjM Software. Gleneden Beach, Oregon, USA.

46. Mcmillen, D. P. 2001. Nonparametric employment subcenter identification. Journal of Urban economics, 50, 448-473.

47. Meyer, M. D. \& Miller, E. J. 2001. Urban transportation planning, Mc Grow Hill, USA.

48. Monajem, S. \& Nosratian, F. E. 2015. The evaluation of the spatial integration of station areas via the node place model; an application to subway station areas in Tehran. Transportation Research Part D: Transport and Environment, 40, 14-27.

49. Nasri, A. \& Zhang, L. 2012. Impact of metropolitan-level built environment on travel behavior. Transportation Research Record, 2323, 75-79.

50. Nasri, A. \& Zhang, L. 2014. The analysis of transit-oriented development (TOD) in Washington, DC and Baltimore metropolitan areas. Transport policy, 32, 172-179.

51. Newman, M. 2010. Networks: an introduction. United Slates: Oxford University Press Inc., New York, 1-2.

52. Pan, H., Li, J., Shen, Q. \& Shi, C. 2017. What determines rail transit passenger volume? Implications for transit oriented development planning. Transportation Research Part D: Transport and Environment, 57, 52-63.

53. Papa, E. \& Bertolini, L. 2015. Accessibility and transit-oriented development in European metropolitan areas. Journal of Transport Geography, 47, 70-83.

54. Papa, E., Moccia, F. D., Angiello, G. \& Inglese, P. 2013. An accessibility planning tool for network transit oriented development: SNAP. Planum, 2(27), 1-9.

55. Park, S., Choi, K. \& Lee, J. S. 2015. To walk or not to walk: Testing the effect of path walkability on transit users' access mode choices to the station. International Journal of Sustainable Transportation, 9 , 529-541.

56. Piovani, D., Molinero, C. \& Wilson, A. 2017. Urban retail dynamics: insights from percolation theory and spatial interaction modelling. Plos one, 12(10): e0185787.

57. Reusser, D. E., Loukopoulos, P., Stauffacher, M. \& Scholz, R. W. 2008. Classifying railway stations for sustainable transitions-balancing node and place functions. Journal of Transport Geography, 16, 191-202. 
58. Roth, C., Kang, S. M., Batty, M. \& Barthélemy, M. 2011. Structure of urban movements: polycentric activity and entangled hierarchical flows. PloS one, 6, e15923.

59. Rousseeuw, P. J. 1987. Silhouettes: a graphical aid to the interpretation and validation of cluster analysis. Journal of computational and applied mathematics, 20, 53-65.

60. Sun, B., He, Z., Zhang, T. \& Wang, R. 2016. Urban spatial structure and commute duration: An empirical study of China. International Journal of Sustainable Transportation, 10, 638-644.

61. Sung, H. \& Oh, J.T. 2011. Transit-oriented development in a high-density city: Identifying its association with transit ridership in Seoul, Korea. Cities, 28, 70-82.

62. Transport for London (TfL). 2015. Assessing transport connectivity in London. London: Transport for London.

63. Transport for London (TfL). 2017. London Underground Performance Report. London: Transport for London.

64. Transport for London (TfL). 2018. Underground services performance. London: Transport for London.

65. Vale, D. S. 2015. Transit-oriented development, integration of land use and transport, and pedestrian accessibility: Combining node-place model with pedestrian shed ratio to evaluate and classify station areas in Lisbon. Journal of transport geography, 45, 70-80.

66. Vale, D. S., Viana, C. M. \& Pereira, M. 2018. The extended node-place model at the local scale: Evaluating the integration of land use and transport for Lisbon's subway network. Journal of Transport Geography, 69, 282-293.

67. Van Nes, A. \& Stolk, E. 2012. Degrees of sustainable location of railway stations: Integrating space syntax and node place value model on railway sations in the province of North Holland's strategic plan for 20102040. Proceedings of the 8th International Space Syntax Symposium, January 3-6, 2012, Santiago de Chile, Chile.

68. Wang, F., Chen, C., Xiu, C. \& Zhang, P. 2014. Location analysis of retail stores in Changchun, China: A street centrality perspective. Cities, 41, 54-63.

69. Wegener, M. \& Fürst, F. 1999. Land-use transport interaction: state of the art. Deliver-able D2a of the project TRANSLAND (Integration of Transport and Land use Planning). Berichte aus den Insititut fur Raumplanung, Insititut fur Raumplanung, Universitat Dortmund.46.

70. Zemp, S., Stauffacher, M., Lang, D. J. \& Scholz, R. W. 2011. Classifying railway stations for strategic transport and land use planning: Context matters! Journal of transport geography, 19, 670-679.

71. Zhang, M. \& Goodrich, B. 2018. Regional Opportunities and Challenges for Transit-Oriented Development: The Case of the Texas Triangle. University of Texas at Austin. Cooperative Mobility for Competitive Megaregions.

72. Zhong, C., Arisona, S. M., Huang, X., Batty, M. \& Schmitt, G. 2014. Detecting the dynamics of urban structure through spatial network analysis. International Journal of Geographical Information Science, 28 , 2178-2199.

73. Zhao, F., Chow, L.F., Li, M.T., Ubaka, I. and Gan, A., 2003. Forecasting transit walk accessibility: Regression model alternative to buffer method. Transportation Research Record, 1835(1), pp.34-41. 
Supplement A: Correlation Matrix of Node, place and design measures

\begin{tabular}{|c|c|c|c|c|c|c|c|c|c|c|c|c|c|c|}
\hline & y1 & $\mathrm{y}^{2}$ & y3 & $y^{4}$ & y5 & y6 & y7 & $x 1$ & $x 2$ & $\times 3$ & $x 4$ & w1 & w2 & w3 \\
\hline y1 & 1.00 & $0.60^{* * *}$ & 0.00 & $0.30^{* * *}$ & $0.42^{* * *}$ & $-0.28^{* * *}$ & $-0.24^{* * *}$ & $0.40^{* * *}$ & -0.09 & $-.46^{* * *}$ & $0.47^{* * *}$ & 0.12 & $0.50^{* * *}$ & $0.49^{* * *}$ \\
\hline y2 & & 1.00 & -0.05 & $0.34^{* * *}$ & $0.59 * * *$ & $-0.42^{* * *}$ & $-0.38^{* * *}$ & $0.47^{* * *}$ & -0.09 & $0.53^{* * *}$ & $0.56^{* * *}$ & -0.03 & $0.55^{* * *}$ & $0.54^{* * *}$ \\
\hline y3 & & & 1.00 & $0.54^{* * *}$ & -0.02 & $0.31^{* * *}$ & $0.16^{* *}$ & 0.09 & $0.56^{* * *}$ & $-0.23^{* * *}$ & -0.01 & $-0.12^{*}$ & 0.05 & 0.04 \\
\hline y4 & & & & 1.00 & $0.63^{* * *}$ & $-0.14^{*}$ & $-0.42^{* * *}$ & $0.53^{* * *}$ & 0.02 & $0.48^{* * *}$ & $0.55^{* * *}$ & 0.03 & $0.63^{* * *}$ & $0.62^{* * *}$ \\
\hline y5 & & & & & 1.00 & $-0.40^{* * *}$ & $-0.61^{* * *}$ & $0.79 * * *$ & $-0.15^{*}$ & $0.77^{* * *}$ & $0.81^{* * *}$ & 0.09 & $0.88^{* * *}$ & $0.86^{* * *}$ \\
\hline y6 & & & & & & 1.00 & $0.57^{* * *}$ & $-0.28^{* * *}$ & $0.13^{*}$ & $-0.50^{* * *}$ & $-0.36^{* * *}$ & -0.06 & $-0.41^{* * *}$ & $-0.42^{* * *}$ \\
\hline y7 & & & & & & & 1.00 & $-0.45 * * *$ & $0.27^{* * *}$ & $-0.77^{* * *}$ & $-0.58^{* * *}$ & $-0.16^{*}$ & $-0.72 * * *$ & $-0.74^{* * *}$ \\
\hline $\mathrm{x} 1$ & & & & & & & & 1.00 & 0.00 & $0.65^{* * *}$ & $0.81^{* * *}$ & 0.04 & $0.83^{* * *}$ & $0.81^{* * *}$ \\
\hline $\mathrm{x} 2$ & & & & & & & & & 1.00 & $-0.34^{* * *}$ & -0.09 & $-0.14^{*}$ & -0.12 & -0.13 \\
\hline x3 & & & & & & & & & & 1.00 & $0.84^{* * *}$ & $0.18^{*}$ & $0.83^{* * *}$ & $0.83^{* * *}$ \\
\hline$\times 4$ & & & & & & & & & & & 1.00 & 0.09 & $0.88^{* * *}$ & $0.86^{* * *}$ \\
\hline w1 & & & & & & & & & & & & 1.00 & $0.16^{*}$ & 0.15 \\
\hline w2 & & & & & & & & & & & & & 1.00 & $0.89 * * *$ \\
\hline w3 & & & & & & & & & & & & & & 1.00 \\
\hline
\end{tabular}

\section{Supplement B: Centrality of London metro system based on O-D movement network}

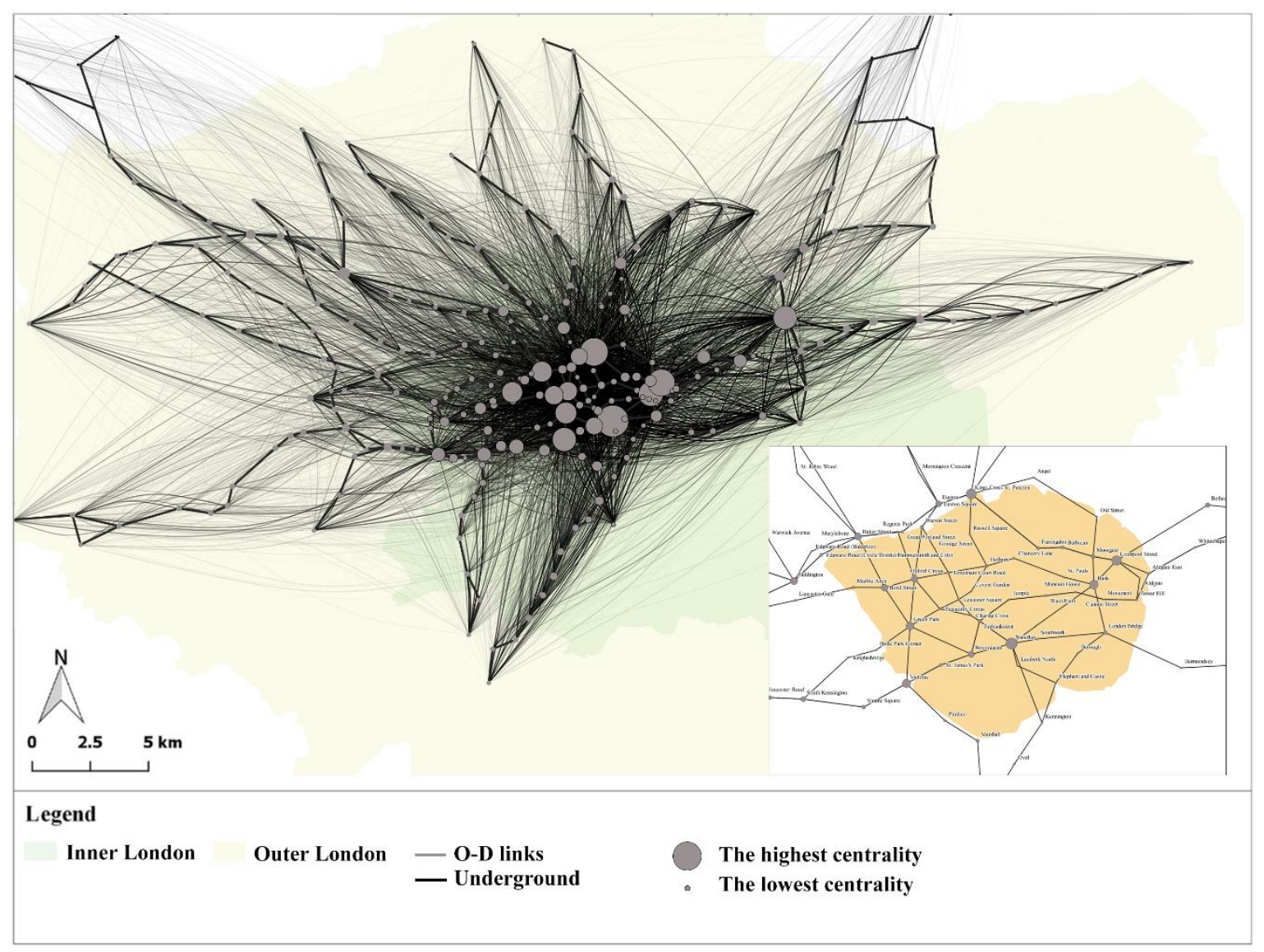

(Note: the size is transformed according to Flannery algorithms in QGIS; the width of OD links indicates the passenger volume) 